\title{
Experiences of Complex Patients With Telemonitoring in a Nurse-Led Model of Care: Multimethod Feasibility Study
}

Kayleigh Gordon ${ }^{1,2}$, RN, MN; Katie N Dainty ${ }^{1,3}, \mathrm{PhD}$; Carolyn Steele Gray ${ }^{1,4}$, PhD; Jane DeLacy ${ }^{5}$, MHSC; Amika Shah $^{1,2}, \mathrm{MScCH}$; Myles Resnick ${ }^{2}$, MSc; Emily Seto ${ }^{1,2}$, PEng, PhD

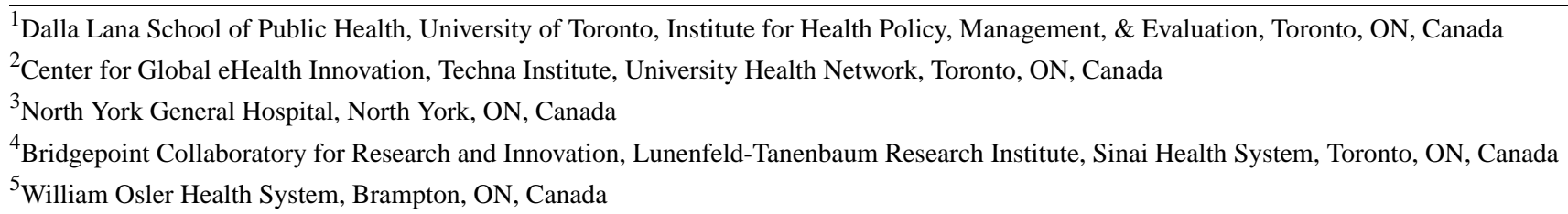

\section{Corresponding Author:}

Kayleigh Gordon, RN, MN

Dalla Lana School of Public Health

University of Toronto

Institute for Health Policy, Management, \& Evaluation

155 College St. 4th Floor

Toronto, ON

Canada

Phone: 14169784326

Email: kayleigh.gordon@mail.utoronto.ca

\section{Abstract}

Background: Telemonitoring (TM) interventions have been designed to support care delivery and engage patients in their care at home, but little research exists on TM of complex chronic conditions (CCCs). Given the growing prevalence of complex patients, an evaluation of multi-condition TM is needed to expand TM interventions and tailor opportunities to manage complex chronic care needs.

Objective: This study aims to evaluate the feasibility and patients' perceived usefulness of a multi-condition TM platform in a nurse-led model of care.

Methods: A pragmatic, multimethod feasibility study was conducted with patients with heart failure (HF), hypertension (HTN), and/or diabetes. Patients were asked to take physiological readings at home via a smartphone-based TM app for 6 months. The recommended frequency of taking readings was dependent on the condition, and adherence data were obtained through the TM system database. Patient questionnaires were administered, and patient interviews were conducted at the end of the study. An inductive analysis was performed, and codes were then mapped to the normalization process theory and Implementation Outcomes constructs by Proctor.

Results: In total, 26 participants were recruited, 17 of whom used the TM app for 6 months. Qualitative interviews were conducted with 14 patients, and 8 patients were interviewed with their informal caregiver present. Patient adherence was high, with patients with HF taking readings on average $76.6 \%$ (141/184) of the days they were asked to use the system and patients with diabetes taking readings on average 72\% (19/26) of the days. The HTN adherence rate was $55 \%(29 / 52)$ of the days they were asked to use the system. The qualitative findings of the patient experience can be grouped into 4 main themes and 13 subthemes. The main themes were (1) making sense of the purpose of TM, (2) engaging and investing in TM, (3) implementing and adopting TM, and (4) perceived usefulness and the perceived benefits of TM in CCCs.

Conclusions: Multi-condition TM in nurse-led care was found to be feasible and was perceived as useful. Patients accepted and adopted the technology by demonstrating a moderate to high level of adherence across conditions. These results demonstrate how TM can address the needs of patients with CCCs through virtual TM assessments in a nurse-led care model by supporting patient self-care and keeping patients connected to their clinical team.

(JMIR Nursing 2020;3(1):e22118) doi: $\underline{10.2196 / 22118}$ 


\section{KEYWORDS}

telemonitoring; adherence; patient experience; complex patients; normalization process theory; implementation; mobile phone

\section{Introduction}

Multimorbidity, defined as the presence of more than one chronic condition in an individual [1], has been increasing, particularly in patients with $\geq 4$ to 5 conditions [2]. The associated risks of patients with chronic conditions include frequent hospitalizations, which can lead to increased risks of hospital-acquired infections and longer length of stay [3-5]. Previous qualitative research highlights numerous struggles patients experience in trying to manage their conditions [6], including a high treatment burden in self-managing their care, attending multiple appointments, polypharmacy, and adhering to complex care regimens [7,8]. As defined, multimorbidity does not account for common dispositions, such as frailty or aging, which may contribute to ineffective management and unanticipated outcomes. Patients with complex chronic conditions (CCCs) include both those with multimorbidity who also face complex social challenges such as socioeconomic vulnerability [9]. The layers of physical, mental, and social conditions cause extensive clinical variability in this patient population.

Several studies have found that nurse-led models enable patients to spend more time with clinicians and coordinate care under a more comprehensive and holistic approach, rather than just a single-disease focus [10-12]. Previous studies have also concluded that nurse-led models of care are feasible to deliver comprehensive chronic disease management [10,12-15] due in part to the broad scope of nursing practice, holistic approach, and interprofessional team of providers among other factors. A recent study focusing on patients with CCCs demonstrated that nurse practitioner (NP)-led care models provide sufficient quality and competency in diabetes and multimorbidity care [16]. Other studies have also found that nurse-led models of care are a potential mechanism to serve chronic populations, particularly when technology can complement patient self-care at home [15,17].

Several systematic reviews have shown that the use of telemonitoring (TM) can lead to improved health outcomes [18-23] and reduced hospital readmissions [18,24-26]. TM has also been shown to reduce all-cause mortality from heart failure (HF) $[19,22,23,27]$, improve hemoglobin $A_{1 c}$ in patients with diabetes mellitus (DM) [28-31], improve blood pressure (BP) for patients with hypertension (HTN) [28,32,33], and reduce respiratory exacerbations in patients with chronic obstructive pulmonary disease [24]. Studies also indicate that TM can improve shared decision making [34,35] and patient experience with care $[15,36]$. However, several large TM trials have also reported mixed results [23,31,37-40]. It is possible that inconsistent findings are not only because of the technology itself but also because of the specific chronic conditions, combination of conditions, or lack of conditions targeted in the research. The model of care delivery in which the technology is implemented may also influence overall adherence. In particular, TM for patients with CCCs has not been widely studied in nurse-led models of care.

To address this gap, we evaluated the feasibility and perceived usefulness of the Medly TM system in a nurse-led care model for patients with CCCs. Feasibility is defined as the extent to which a new innovation can be successfully used or carried out within a given agency or setting [41]. The results of the implementation from the perspectives of the care team will be presented elsewhere. To the best of our knowledge, this is the first implementation of a TM system specifically targeting patients with CCCs within a nurse-led model of care. Our study was guided by the following central research question: What is the feasibility and perceived usefulness of a multi-condition TM platform in an integrated nurse-led care model?

\section{Methods}

\section{Study Design Overview and Setting}

A pragmatic, multimethod 6-month feasibility study was conducted for patients with CCCs in a nurse-led care clinic in Southern Ontario. The needs of patients and their families were identified in a previous qualitative study that informed the clinic's ongoing optimization [15]. Referral criteria to the NP-led CCC clinic included patients with multimorbidity; at least one hospitalization or more than two emergency visits within the last 6 months; and a length of stay, acuity of admission, comorbidities, and emergency department visits score $>5$ of a total of 14 [42]. The TM feasibility study commenced approximately 12 months after the clinic launch. Patients with HF, HTN, and/or DM involved in the study were asked to take frequent physiological readings at home via Medly, as per Table 1. All research activities were undertaken with approval from the William Osler Office of Research Ethics (\#18-0061), the University Health Network Research Ethics Board (\#18-5667), and the University of Toronto Research Ethics Board (\#37660).

Table 1. Frequency of telemonitoring readings per condition and required measures per telemonitoring algorithm.

\begin{tabular}{lll}
\hline Condition & Frequency of readings & Physiological measures \\
\hline Heart failure & Daily & Blood pressure, heart rate, weight, and symptoms \\
Hypertension & $\times 1$ every 2 weeks & Blood pressure \\
Diabetes & $\times 1$ per week & Blood sugar \\
\hline
\end{tabular}




\section{Theoretical Framework}

A pragmatic worldview was taken to evaluate the social construction of feasibility in multi-condition TM using the normalization process theory (NPT) by May [43-46] and the Framework of Implementation Outcomes (IOs) by Proctor et al [41]. The relationship between the 4 constructs of NPT (coherence, cognitive participation, collective action, and reflective monitoring) was evaluated using a multimethods approach in the context of the patient's experiences of using the TM platform in the nurse-led care model. NPT was used to map the implementation process of multi-condition TM in patients with CCCs from the patient's perspective (Textbox 1), whereas the IOs were used to determine the success or failure of the implementation using the constructs of acceptability, appropriateness, adoption, and fidelity (Textbox 2). The outcome constructs of cost, penetration, and sustainability were not specifically assessed as this study focused on the evaluation of feasibility through the patient experience and not on the model of care delivery (ie, service outcomes) or health outcomes (ie, client outcomes).

Textbox 1. Normalization process theory constructs and definitions.

- Coherence

Sense making and understanding the purpose of the potential of the telemonitoring (TM) intervention

- Cognitive participation

Commitment and decision from patient (and caregivers) to commit to the work of the intervention

- $\quad$ Collective action

The work that patients (and caregivers) do to engage with the TM intervention

- $\quad$ Reflexive monitoring

Reflection and appraisal of the TM intervention

Textbox 2. Implementation Outcomes constructs and definitions by Proctor.

- Appropriateness

Perceive relevance or compatibility of the innovation for a given setting or perceived fit of the innovation to address a particular issue

- Acceptability

Perception among patients that a given intervention (ie, telemonitoring [TM]) is agreeable or satisfactory

- Adoption

Initial decision or action to use an intervention (ie, TM)

- $\quad$ Feasibility

Extent to which a new intervention can be successfully used within a given setting

- $\quad$ Fidelity

Degree to which the intervention (ie, TM) was used as intended in practice

\section{The TM Intervention}

Medly is a smartphone-based chronic disease TM platform that was developed by researchers at the University Health Network in Toronto, Ontario [27,47-49]. The central component of Medly is an app that enables patients to monitor physiological measurements (ie, BP, weight [WT], blood sugar, etc) with wireless home medical devices and to answer simple symptom questions. Readings are processed through a clinically validated algorithm embedded in the app, which is contextualized to an individual's target range. Patients receive real-time self-care instructions, and their clinicians are alerted at the earliest signs of readings outside their individually curated normal range. Using the Medly app, patients were able to view graphical trends of each physiological reading over time. To assist with adherence, an automated phone call was implemented based on the required frequency of each condition's algorithm. This call was only sent out if patients missed a reading and could be disabled on patients' request. Participants were provided with all the necessary equipment, including a smartphone, home medical devices such as a weight scale or BP monitor, and batteries. In this case, Medly was designed to monitor HF, HTN, and DM (Figure 1). 
Figure 1. Screenshots of the Medly app for patients with a complex chronic condition.

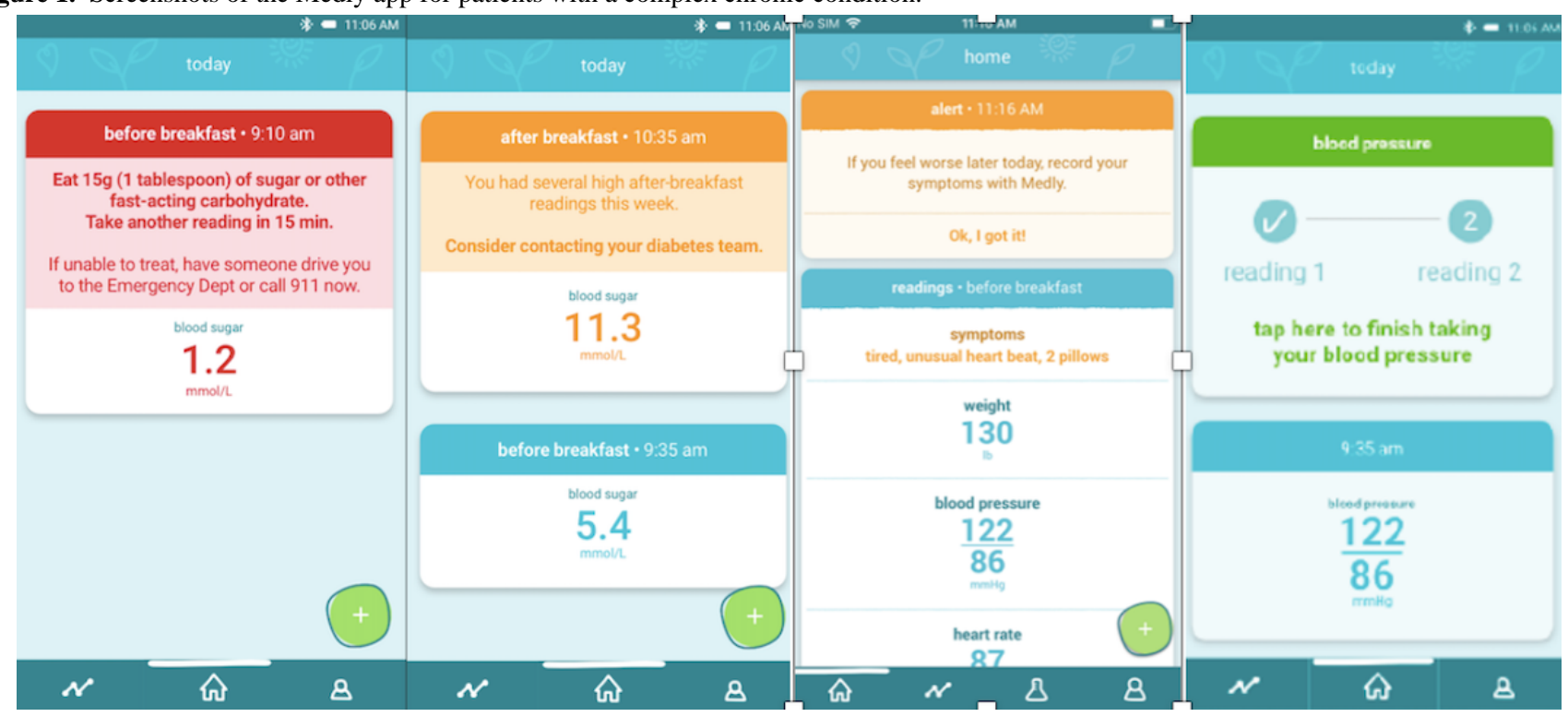

\section{Participant Sampling and Recruitment}

Between May and July 2019, patients were recruited through convenience sampling during their routine visit to the nurse-led clinic. Researchers did not specifically identify patients with a specific combination of conditions, as the intent was an evaluation of feasibility. A sample of 15 to 25 participants based on specific inclusion criteria was deemed to provide sufficient data to explore the feasibility of TM in a nurse-led clinic, including reaching saturation for the patient interview data [50,51].

Patients were eligible to participate if they (1) were aged at least 18 years; (2) were able to take home measurements as intended; (3) were diagnosed with HF, HTN, or DM and one additional chronic condition; and (4) could understand English. Patients were excluded if they had visual or cognitive impairments that would prevent them from using the system or if they were already enrolled in a TM program. The NP identified which of the 3 conditions (HF, HTN, and/or DM) or a combination of conditions should be monitored for each participant. On written consent, the patient was provided with the necessary equipment and given an in-person training session on how to use the TM equipment. The NP set the specific algorithm ranges for each patient through a clinical dashboard. Patients were followed up with the Medly system for 6 months.

\section{Quantitative Data Collection and Analysis}

Patient adherence to taking readings was quantitatively assessed by analyzing the server logs of the TM system. Adherence was used as a measure to indicate TM's acceptability in this context and as an indicator of the perceived usefulness of TM. In this case, adherence was used as a pertinent implementation factor to determine feasibility [41] and was evaluated by measuring the frequency of TM readings for each condition (Table 1). For $\mathrm{HF}$, as patients were instructed to take daily readings, adherence was measured as the percentage of days readings were taken over 6 months. For HTN, as per the algorithm, adherence was measured as the percentage of time patients took 2 consecutive $\mathrm{BP}$ readings at least once every 2 weeks. For DM, adherence was defined by taking readings at least once per week during the 6-month study.

Questionnaires were administered at the start and end of the study. Questionnaires included 3 sections: (1) the 36-Item Short Form Survey (SF-36) was used as a baseline indicator to evaluate the overall health status [52] of our participant group, (2) a series of technology questions were utilized to better understand the demographics of whom multi-condition TM is feasible within a nurse-led model, and (3) the participants' level of comfort with technology. Determining statistical significance in a small feasibility study was not the goal of including the SF-36 tool but rather to contextualize patient health status data in this care model. A chart review was conducted to collect basic demographic information (ie, age, sex, marital status, education level, etc). Sociodemographic data and clinical histories for all participants were summarized using a descriptive analysis.

\section{Qualitative Data Collection and Analysis}

All participants were invited to participate in a poststudy interview, each lasting between 30 and $60 \mathrm{~min}$. Interviews were conducted onsite or over the telephone upon study completion. A semistructured interview guide was developed, informed by the 4 constructs of NPT (Multimedia Appendix 1) [43,44,53]. Participants were asked to describe their experiences and perspectives on using the TM system. Caregivers were not asked any specific questions during the interview but were able to participate in the discussion. All interviews were audio taped and transcribed verbatim for analysis.

An interpretative descriptive approach was used to guide the qualitative analysis [54,55], as this approach examines a clinical phenomenon with the goal of identifying themes and patterns among subjective perspectives while also accounting for variations between individuals [56]. The process of inductive thematic analysis followed the method outlined by Thorne et al [54], starting with an initial reading of each transcript. Subsequent readings included coding salient ideas and inductively deriving conceptual themes, first within and 
subsequently across transcripts. Detailed notes and codes were grouped according to emerging themes. The inductive process was conducted independently by 2 researchers (KG and AS) who came together to discuss emerging codes. Disagreements were discussed together and with the larger research team to reach consensus. Together, inductive codes were then compared with the implementation process constructs (NPT $[43,44,46]$ ) and the outcomes of patient experience (IOs by Proctor et al [41]) to structure the evaluation of the feasibility of this care model [41]. Saturation occurred at a point at which the codebook stabilized, a consensus was reached between the 2 researchers, and no additional codes or themes were identified in the data $[57,58]$.

\section{Results}

\section{Study Participants}

In total, 26 participants identified by the team agreed to participate. Of the 26 participants, 18 were put on $\mathrm{HF}$ monitoring, 1 on DM, 1 on HTN, 5 on HF+DM, and 1 on HTN+DM. The remaining 8 patients were removed from the TM system for several reasons, including winter relocation $(n=1)$, rehabilitation admission $(n=1)$, unanticipated language barrier $(n=1)$, inability to use a smartphone touchscreen $(n=4)$, and death $(\mathrm{n}=1)$.

Table 2 presents the characteristics of the participants who completed the study. Overall, 65\% (17/26) of the participants used the system for the full 6 months. The age of the participants ranged from 44 to 91 years, with a mean age of 73.8 (SD 13.3) years. All the study participants had more than 3 chronic conditions, with some participants having more than 8 conditions in total. The total number of medications ranged from 8 to 19 per participant. This feasibility study was conducted in a geographic area that had a high percentage of recent immigrants, with more than $42 \%$ of the city's residents being born outside Canada [59]. Approximately $60 \%$ of the participants were identified as non-white. The level of education also varied widely across participants, with $35 \%$ having not completed high school and $35 \%$ having completed a college or university degree. With regard to technology experience, 11 of the $17(65 \%)$ participants who completed the questionnaire stated that they owned a cellphone $(n=4)$ or smartphone $(n=8)$, whereas 3 participants did not specify which kind of device (Table 3). Only one participant had previously used a TM system, although it was not smartphone-based TM or multi-condition-based TM. Despite more than half of the participants owning a cellphone or smartphone, the comfort level across the participants was mixed. In the end, the response rate for the prestudy questionnaire was fairly high $(16 / 17,94 \%)$ but lower for the poststudy (10/17, 59\%) questionnaires. One participant did not complete a prestudy questionnaire. An evaluation of the SF-36 data did not find any meaningful results, likely because of the low poststudy response rate. 
Table 2. Characteristics of participants who completed the study.

\begin{tabular}{|c|c|}
\hline Characteristics & Values, $\mathrm{n}(\%)$ \\
\hline \multicolumn{2}{|l|}{ Sex } \\
\hline Female & $9(53)$ \\
\hline Male & $8(47)$ \\
\hline \multicolumn{2}{|l|}{ Ethnicity } \\
\hline White & $5(42)$ \\
\hline Non-White & $12(58)$ \\
\hline \multicolumn{2}{|l|}{ Age (years) } \\
\hline $40-49$ & $1(6)$ \\
\hline $50-59$ & $3(18)$ \\
\hline $60-69$ & $3(18)$ \\
\hline $70-79$ & $4(23)$ \\
\hline $80-89$ & $4(23)$ \\
\hline $90-99$ & $2(12)$ \\
\hline \multicolumn{2}{|l|}{ Marital status } \\
\hline Never been married & $2(12)$ \\
\hline Married or living with a partner & $6(35)$ \\
\hline Separated or divorced & $2(12)$ \\
\hline Widowed & $6(35)$ \\
\hline Missing or unknown & $1(6)$ \\
\hline \multicolumn{2}{|l|}{ Highest completed level of education } \\
\hline Less than high school & $6(35)$ \\
\hline High school & $4(24)$ \\
\hline Trade or technical training after high school & $1(6)$ \\
\hline College or university undergraduate & $6(35)$ \\
\hline
\end{tabular}


Table 3. Participants' experience with cellphones or smartphones.

\begin{tabular}{|c|c|}
\hline Technology questions & Response, $\mathrm{n}(\%)$ \\
\hline \multicolumn{2}{|c|}{ Own a cellphone or smartphone $(n=17)$} \\
\hline Yes & $11(65)$ \\
\hline No & $6(35)$ \\
\hline \multicolumn{2}{|l|}{ If so, which kind? (n=11) } \\
\hline Cellphone & $4(36)$ \\
\hline Smartphone & $4(36)$ \\
\hline Unknown & $3(27)$ \\
\hline \multicolumn{2}{|c|}{ Comfort level using a smartphone or cellphone $(n=17)$} \\
\hline Not comfortable & $4(23)$ \\
\hline Somewhat comfortable & $3(18)$ \\
\hline Comfortable & $3(18)$ \\
\hline Very comfortable & $4(23)$ \\
\hline Unknown & $3(18)$ \\
\hline \multicolumn{2}{|c|}{ What features do you use on a smartphone? $(n=17)$} \\
\hline Voice calls or text messaging & $8(47)$ \\
\hline Internet & $6(35)$ \\
\hline Video & $3(18)$ \\
\hline Apps or games & $4(23)$ \\
\hline Other & $0(0)$ \\
\hline \multicolumn{2}{|c|}{ If you own a smartphone, what activities do you use it for? $(n=17)$} \\
\hline Email & $4(23)$ \\
\hline Information seeking & $5(29)$ \\
\hline Scheduling & $2(12)$ \\
\hline Information storage & $6(35)$ \\
\hline Recreation & $5(29)$ \\
\hline Other & $3(18)$ \\
\hline Unknown & $2(12)$ \\
\hline
\end{tabular}

\section{Adherence Results}

Of the 17 patients who completed the study, 13 patients used the HF module, 1 patient used the HTN module, 2 patients used the HF+DM modules, and 1 patient used the HTN+DM modules. One participant (MCCP008) was initially monitoring HF and DM but was later offboarded from the DM component because of a change in health status.

Adherence to each condition was evaluated independently, irrespective of the combination of conditions. The adherence for each patient with HF is displayed in Table 4. The evaluation of adherence to HF was divided into 2 categories: the number of days patients took just the physiological readings (BP/HR/WT) and the number of days patients took all required physiological readings and completed symptom questions (full set). Although individual usage patterns varied across the participants, patients took physiological readings (BP/HR/WT), on average, over $77.2 \%(142 / 184)$ of days of the expected reported days. Of the patients with HF, 56\% (9/16) were adherent to physiological readings over $80 \%$ of the days on TM, and $31 \%(5 / 16)$ were adherent over $90 \%$ of the days on TM. One patient (MCCP0017) took a full set of readings over $99 \%$ $(183 / 184)$ of the days on TM. When evaluating the percentage of days that patients took all 3 physiological readings and symptom questions (ie, full set), the percentage dropped to $69.0 \%(127 / 184)$.

Overall, adherence in the HTN module was 55\% (29/52) on average. HTN adherence was defined as taking at least one reading every 2 weeks. However, participants using the HTN component of the system, on average, took readings more frequently than required by the algorithm (Figure 2). DM adherence was on average $72 \%(19 / 26)$ defined as taking at least one reading per week (Figure 3 ). 
Table 4. Heart failure adherence of physiological measures versus full set $(\mathrm{N}=184)$.

\begin{tabular}{|c|c|c|c|c|}
\hline Study ID & $\begin{array}{l}\text { Number of days taking } \\
\mathrm{BP}^{\mathrm{a}} / \mathrm{HR}^{\mathrm{b}} / \mathrm{WT}^{\mathrm{c}}, \mathrm{n}\end{array}$ & $\begin{array}{l}\text { Percentage of days taking } \\
\text { BP/HR/WT, n }(\%)\end{array}$ & Days taking full set, n (\%) & $\begin{array}{l}\text { Percentage delta for adher- } \\
\text { ence, } \%\end{array}$ \\
\hline МCCP002 & 163 & $163(88.6)$ & $155(84.2)$ & -4 \\
\hline МCCР005 & 134 & $134(72.8)$ & $122(66.3)$ & -7 \\
\hline МССР006 & 167 & $167(90.8)$ & $163(89.6)$ & -2 \\
\hline МCCP007 & 147 & 147 (79.9) & $137(74.5)$ & -5 \\
\hline МССР008 & 112 & $112(60.9)$ & $105(57.1)$ & -4 \\
\hline МССР009 & 177 & $177(96.2)$ & $177(96.2)$ & 0 \\
\hline МССР0012 & 178 & $178(96.7)$ & $96(52.2)$ & -45 \\
\hline МССР0013 & 28 & $28(15.2)$ & $11(5.9)$ & -9 \\
\hline МССР0014 & 146 & $146(79.3)$ & 143 (77.7) & -2 \\
\hline МССР0017 & 181 & $181(98.4)$ & $179(97.3)$ & -1 \\
\hline МССР0018 & 157 & $157(85.3)$ & $151(82.1)$ & -3 \\
\hline МССР0019 & 50 & $50(27.2)$ & $12(6.5)$ & -21 \\
\hline МССР0022 & 170 & $170(92.4)$ & $165(89.7)$ & -3 \\
\hline МССР0024 & 139 & $139(75.5)$ & $121(65.8)$ & -10 \\
\hline МССР0025 & 160 & $160(87.9)$ & $156(84.8)$ & -2 \\
\hline
\end{tabular}

${ }^{\mathrm{a} B P}$ : blood pressure.

${ }^{b}$ HR: heart rate.

${ }^{\mathrm{c}} \mathrm{WT}$ : weight.

Figure 2. Total number of blood pressure readings on the hypertension modules. BP: blood pressure.

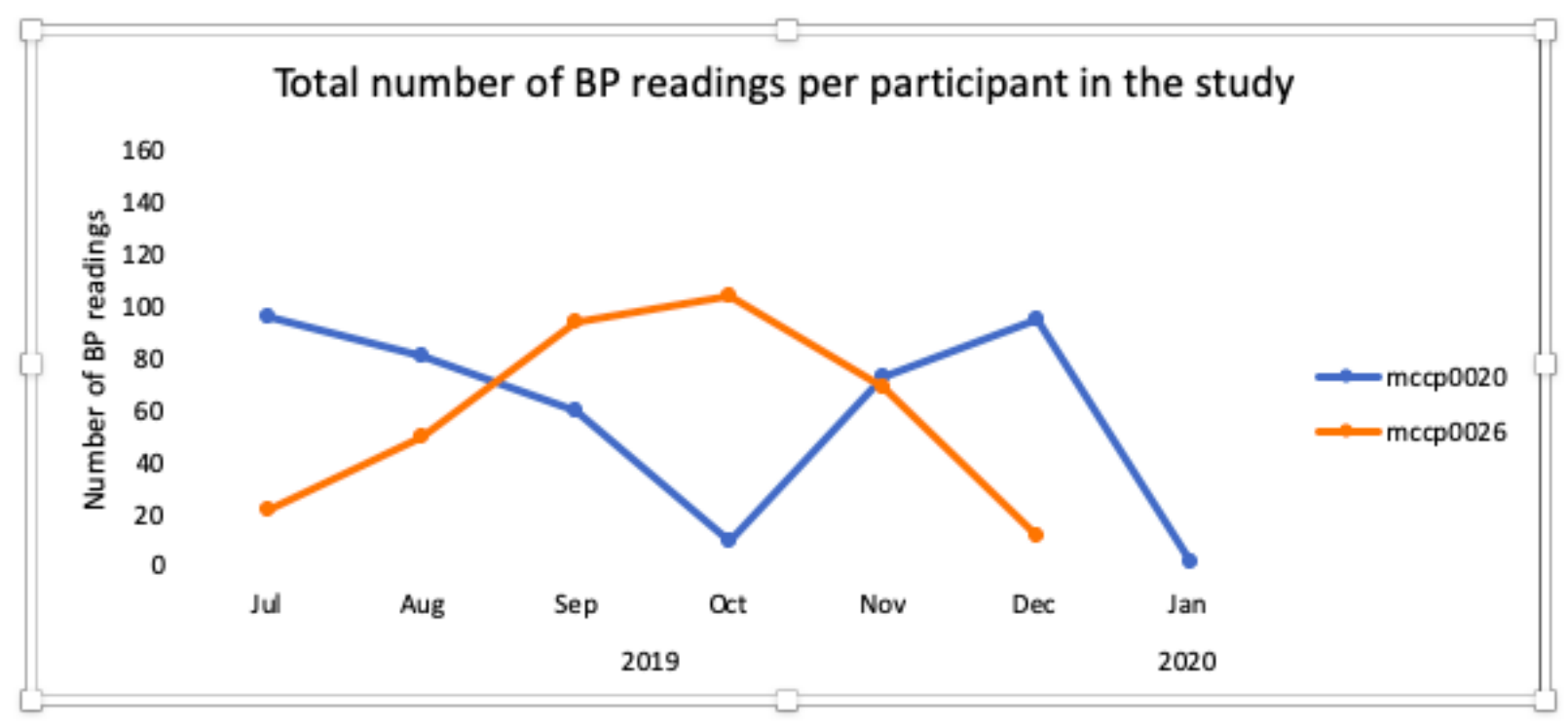


Figure 3. Total number of blood glucose readings on the diabetes mellitus modules. BG: blood glucose.

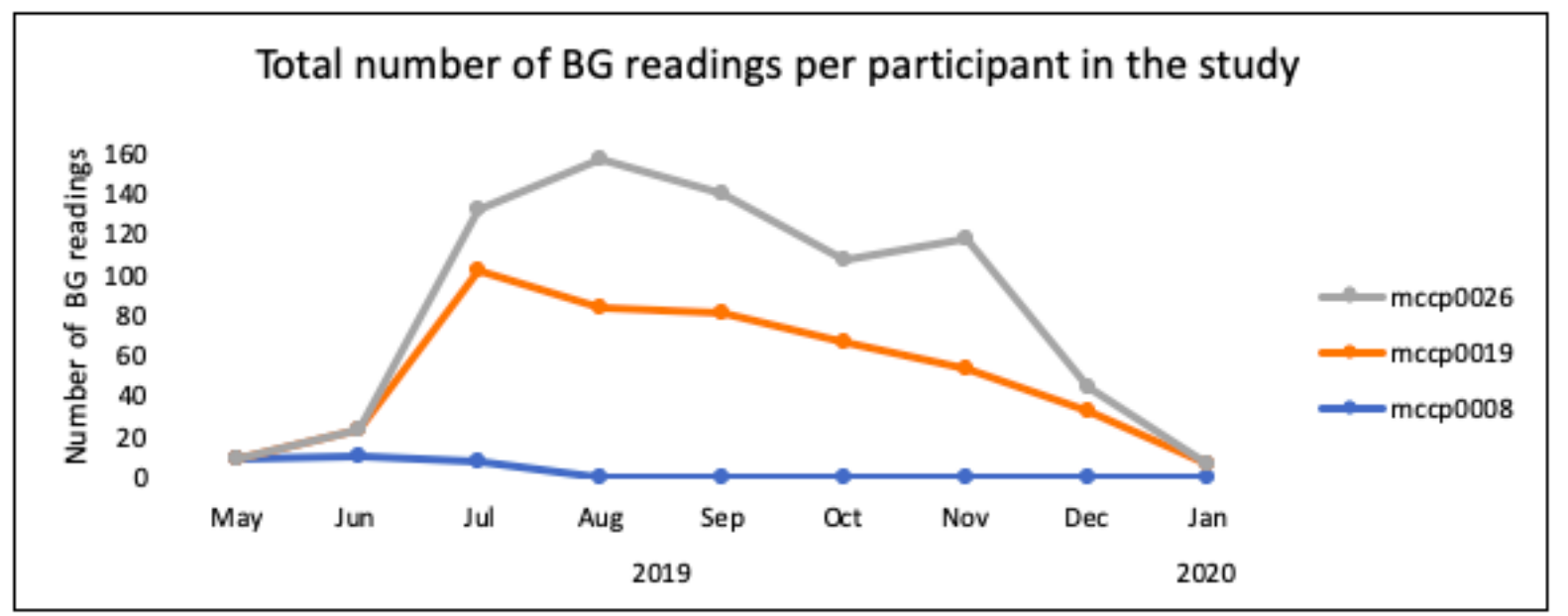

\section{Results From Qualitative Data}

The qualitative findings of the patient experience can be represented by 4 main themes and 12 subthemes. The main themes were (1) making sense of the purpose of TM, (2) engaging and investing in TM, (3) implementing and adopting $\mathrm{TM}$, and (4) perceived usefulness and perceived benefits of TM in CCCs. The themes and subthemes were mapped together with the constructs within NPT and IOs as shown in Table 5. 
Table 5. Mapping of overarching themes and subthemes to the normalization process theory and the Implementation Outcomes framework by Proctor.

Theme and subthemes
Making sense of the purpose of TM"
"We were keeping a log book and it wasn't consistent but
we were still trying to do that...The NP would have me
email her the sugar readings. So I would have to transpose
all that information into an email... they would review it
when we go visit them." (MCCP0019)

\section{Engaging and investing in TM}

Comparing the old ways of working to use TM

Connected devices support individual capacity and gain investment for patient buy-in of TM practices

Accepting the technology

"We did] nothing. If we felt sick we'll go to the doctor. We took blood pressure now and again, but not on a regular basis, not like this." (MCCP0025)

"I think it was we actually really liked that it was connected, because it gave me a peace of mind. At least I know, okay, if something goes wrong, there's somebody there to call her. Someone is kind of checking on me." (MCCP0026)

"Yes, it was easy. Yeah it does everything for you. You just have to turn the phone off and press the button the blood pressure cuff or step on the weight scale and it does everything." (MCCP009)

\section{Implementing and adopting TM}

Adjusting routines around $\mathrm{TM}$

Frequent clinical monitoring; reinforced routine adherence

The support of caregivers and caregiver participation

\section{Evaluating perceived usefulness and perceived benefits of TM in $\mathrm{CCCs}^{\mathrm{b}}$}

Improvement to ongoing self-care practices

Enabling immediate action on abnormal readings and trends

Concerns moving forward without TM

Symptom questions were not always relevant for patients with $\mathrm{CCCs}$
"You get up, you put your housecoat on, you go to the bathroom, you get the scale out from under the sink." (MCCP007)

"It's good. It's good to know that somebody is out here watching too not negatively. If they were watching to condemn me for what I'm doing - but they're watching with my best interests." (MCCP002)

"Yeah, so it's one hundred percent good to have help from family members." (MCCP0019)

"You don't know whether it's good or bad, but with Medley they give that guideline to live with - within" (MCCP002)

"I know if the reading comes up in orange-that's the orange. If it comes up in orange, check. If it gets worse during the course of the day check the clinic. And I know that feels good. I feel good. Yeah, I feel good, so that is very helpful, that is very, very helpful." (MCCP002)

"Yeah. I like knowing someone's keeping an eye on me. Certainly no one else will keep an eye on me now. [After I you mean?] Yes, there's no one now...I just liked it, that's all, knowing, they were there looking out for me." (MCCP0024)

"There were times [when it was] kind of like a grey area...She's not always feeling great and you enter the information based on the prompts and some of those prompts alerted the nurse at the hospital and we would get a phone call. And sometimes to me they were kind of unwarranted.. Was she dizzy? Well she feels dizzy a lot of times. She's usually OK." (MCCP0019's caregiver)
Normalization process theo- Implementation Outcomes ry construct construct by Proctor

Coherence Appropriateness

${ }^{\mathrm{a}} \mathrm{TM}$ : telemonitoring.

${ }^{\mathrm{b}} \mathrm{CCC}$ : complex chronic condition. 


\section{Theme 1: Making Sense of the Purpose of TM}

The first theme synthesizes participants' accounts of how they made sense of TM, from the initial introduction to the technology to understand its purpose to enable a more structured method of physiological monitoring to connect patient information to the clinic. Participants described the process of measuring physiological readings such as BP or blood sugar at home to track their conditions for their care team. Participants were familiar with the process of keeping a logbook to track readings taken between appointments:

We were keeping a log book and it wasn't consistent, but we were still trying to do that...

The nurse practitioner would have me email her the sugar readings. I would have to transpose all that information into an email for her.. other than that everything was just in the log book and they would review it when we go visit them. [MCCP0019]

One participant described how the ability to go back and look at previous readings made sense in terms of alleviating the challenge of maintaining up-to-date logs at home (ie, appropriateness). Often, manual tracking did not work because of inconsistent patient-provider communication or the inability to recall context-specific readings.

\section{Theme 2: Engaging and Investing in TM}

By comparing the patients' current care practices at home (ie, $\operatorname{logs}$ ) and envisioning new work of taking digital remote readings, patients began to engage in using TM. Instead of calling in readings, by taking readings through the app, they were sent automatically to the clinic. This supported the relational work necessary to gain buy-in from patients to accept the technology and to invest time in a remote way of care.

\section{Comparing the Old Ways of Working to Using TM}

Before the introduction of the TM intervention, there was significant variability in the frequency of participants taking physiological readings at home routinely. Almost all participants described taking physiological readings on occasion at home, in a doctor's office, or at a local pharmacy. One participant described their monitoring processes before beginning TM as irregular:

[We did] nothing. If we felt sick we'll go to the doctor. We took blood pressure now and again, but not on a regular basis, not like this. [MCCP0025]

One patient participant noted that she had difficulty making in-person appointments, often canceling because of the weather conditions or too many appointments. By engaging with TM, she could still receive care remotely, avoiding winter driving conditions. This contributed to increased investment in a connected TM system:

It's hard to make appointments in this weather because you don't know what I have to come through from [city name]. You can have a big weather difference between here and there... It's hard to make every appointment with so many. I've had two this week already. Another at 2 and then 230 today, plus one yesterday. [MCCP0024]

\section{Connected Devices Support Individual Capacity and Gain Investment for Patient Buy-In of TM Practices}

Having the devices connected directly to the clinic supported buy-in from patients through increased patient-clinician communication, thereby building their capacity at home (ie, saving time, providing new information to manage their care, and connecting with their personal clinicians). The ability to visualize live data and provide reassurance that someone was looking out for their health generated recurring engagement with TM and an investment to continue using the system at home:

We were keeping a log book and it wasn'tconsistent but we were still trying to do that and we're going to have to go back to that unfortunately after this... Having this was better for us and at least for the hospitals because they could see live data right there in their systems. [MCCP0019]

\section{Accepting the Technology}

Several participants were hesitant about the process of learning TM. Initially, several participants described the smartphone as challenging. Some participants seemed to rely more on help from family members or other informal caregivers to use TM than others:

So, the phone itself was a bit of a challenge at first. I thought "How do I go back? Where's the back button?" All I had to do it phone you, but I figured it out... That was a little bit of a frustration...sometimes it's better learning on your own. [MCCP0024]

Overall, most patients engaged and accepted the technology over time, describing it as easy to use. The tasks required to complete a morning reading aligned with what their care team, particularly the nurse, was already asking them to do at home.

\section{Theme 3: Implementing and Adopting TM}

This theme describes the process of enabling the patient's work to implement TM at home and how these practices led to a decision to adopt the intervention seamlessly into their normal routine.

\section{Adjusting Routines Around TM}

The patient's work of using TM frequently became a part of their everyday routine. Along with getting up, going to the bathroom, and taking their medication, taking readings was described as a normal step in this everyday process:
In the morning time when I wake up and go to the bathroom, I take my water tablet before I eat, to pass the water out. Then I test my pressure, weight, and the heart rate using Medly. [MCCP006]

On the basis of the readings, patients would adjust the tasks they had done every day, for example, monitoring fluid intake or restricting salt intake.

\section{Frequent Clinical Monitoring and Reinforced Routine Adherence}

Participants described that they perceived someone was looking out for them (ie, nurse) and taking care of them in the virtual 
background (ie, nurse-led team). The registered nurse acted as a central point of contact within the care model that could address varying symptoms, cross-condition needs, and concerns. This created a mechanism that reinforced routine adherence and continued use of the TM system over time. Some participants described feeling more confident of their health knowing that someone was watching him and would reach out if something was wrong:

\section{One thing I know is that I'm being watched. I'm being monitored. It's nice. If something is wrong they'll know too and Medly will get in touch. It makes you more aware of what's going on inside your body. [MCCP0025]}

When the clinicians would call to follow up on an abnormal reading or missed reading, participants described it as reassuring and helpful. Participants came to rely on immediate feedback not only from the team but also from the self-care messages delivered by the app:

Whenever something was wrong, the nurse would call, so it was very helpful... But like I said a couple times they just called us because of a reading they got. [MCCP0022]

\section{Support of Caregivers and Caregiver Participation}

Participants were trained to use the TM system individually before starting the study. Although a caregiver was not required for use, 11 of 17 (65\%) participants had support at home. During the poststudy interviews, it was clear that caregivers heavily participated throughout the TM process, despite whether the support was necessary:

The blood pressure taking-I have arthritis, I have rheumatism... It's hard for me to do anything with my fingers. So it was good to have somebody to help me that way. [MCCP0014]

But if I have any problems with the cell phone, I got from Medly, I will call my wife and she would play with it because I don't have to know all this. [MCCP002]

\section{Theme 4: Evaluating Perceived Usefulness and Perceived Benefits of TM for CCCs}

In conclusion, all participants seemed to appraise the TM system as if it was already an embedded part of their daily routine in normal life. Participants described improvements in self-care knowledge, such as being able to identify when something was not right even if they felt no physical symptom differences. This enabled action on abnormal readings they may not have identified without Medly. Participants shared that clinicians would often quickly reach out to discuss abnormal findings. Participants described a strong desire to continue monitoring, even after the study ended. Despite high adherence rates, several technical issues presented minor challenges.

\section{Improvements to Ongoing Self-Care Practices Using TM}

One participant described his self-care practices before TM as just a guessing game (MCCP007) without clear direction or understanding how to improve this own care at home:

I was just winging it because I didn't know anything
about it at all, I weighed myself, but there was no
concept behind that... now with the weight and the
blood pressure together and the correlation that goes
that... that aspect indicating my health [overall], it
is, it was beautiful it helped me keep myself in check.
[MCCP007]

By taking readings daily, patients described getting to know their target range (ie, reflexive monitoring). Participants described how the device data kept them informed, improving their knowledge of their condition, and how they could keep track of their health over time (ie, feasibility).

\section{Enabling Immediate Actions on Abnormal Readings and Trends}

All participants referenced how Medly could identify when a reading or trend was not right. Many patients specifically noted using the color to identify the severity of an alert as well as the graphs within Medly to help identify abnormal readings:

When something is not right, your reading comes up
a different color and you know something is wrong,
but you can wait and retake it or you try it again on
the next day. [MCCP0020]

Although participants described differing preferences in how they identified abnormal readings, they described the actions they took to manage these situations:

...with Medly, when it comes up in a different color
it tells you "go to see somebody if it gets worse or if
youfeel worse." And what I like about it is it tells you
what do to... If your weight is not what it should be
it tells your weight... I know if the reading comes up
in orange, check it. If it gets worse during the day, I
check with the clinic. So that is very, very helpful.
[MCCP0022]

Although patients described being able to more clearly identify when something was not right while using TM, many patients still relied somewhat on the nurse-led team to identify abnormalities:

\section{They did call because they were concerned and then we did come into the clinic later that day. So maybe it was a good thing to have Medly that particular time. [MCCP0019]}

When a reading measures outside of the individual tailored range, participants received algorithm-based self-care messages. However, several participants found that clinicians within the model, usually the nurse, would call the patients first:

Because they're usually pretty good. If there is a real critical [reading], they'll try to get us right away. [MCCP0026] 
There were times participants even described their intention to call the nurse in the clinic; several participants noted that the nurse followed up with them before they could reach out.

\section{Concerns Moving Forward Without TM}

Participants expressed strong concerns about having to go back to managing their conditions at home without Medly, even to the point where they were willing to pay for the program out of pocket, or ask what store they could purchase the devices immediately. Participants described a sense of anxiety, knowing that no one would be monitoring their readings going forward:

Yeah. I like knowing someone's keeping an eye on me. Certainly no one else will keep an eye on me now. [After Medly you mean?] Yes, there's no one now...I just liked it knowing, they were there looking out for me. [MCCP0024]

\section{Symptom Questions Were Not Always Relevant for Patients With CCCs}

Several patients described the daily symptom questions as not always relevant or specific enough to isolate subtle changes in their symptoms:

There were times [when it was] kind of like a grey area...She's not always feeling great and we enter the information based on the prompts and some of those prompts alerted the nurse at the hospital. We would get a phone call. And sometimes, to me, they were kind of unwarranted... Was she truly dizzy? Well she feels dizzy a lot of times. She's usually OK. [MCCP0019's caregiver]

\section{Discussion}

\section{Principal Findings}

This study provides a detailed evaluation of the feasibility and perceived usefulness of a multi-condition TM platform using the experiences of patients with CCCs in an integrated nurse-led model of care. Study findings revealed that patients were highly adherent to self-monitoring using multi-condition TM, irrespective of which conditions were monitored at home. A virtual connection to the nurse-led team enabled patient acceptance of this new way of tracking readings at home and engaging in their care using multi-condition TM. By choosing to adopt TM into a daily routine, patients perceived that someone was looking out for them, reinforcing routine adherence and enabling patients to evaluate abnormal readings and trends. Participants perceived TM as useful, describing improved self-care knowledge and acting on information provided by TM in tandem with their nurse-led care team. Evidence of new normal practices was clear (ie, high adherence rates and the patient's detailed descriptions of perceived usefulness of TM), such that ending the study affected this new normal routine.

\section{Theoretical Contribution}

NPT and the IOs framework were used for the structural evaluation of feasibility based on the patient's experience using TM in nurse-led care (Table 5). Using the results, a conceptual framework was developed to visualize the patient experience in light of these constructs (Figure 4).

Figure 4. Mapping normalization process theory to Proctor's Implementation Outcomes in a feasibility study to evaluate multi-condition in nurse-led care.

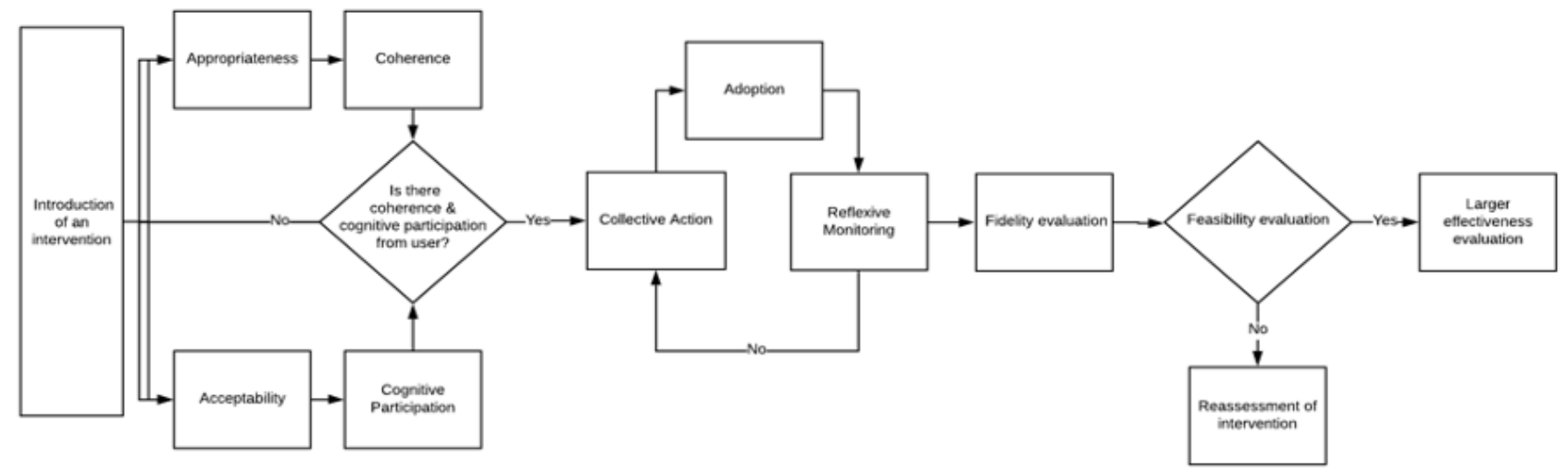

\section{Simultaneous Process of Coherence and Cognitive Participation}

The introduction of multi-condition TM for patients with CCCs in nurse-led care stimulated a simultaneous evaluation of acceptability (Does it make sense to the users?) and appropriateness (Does it fit?). Given these patients had frequent health system encounters that involve evaluating ongoing assessment of physiological indicators, TM of critical physiological measures aligned well with existing care plans (ie, coherence). The results indicated that patients did not always feel physical differences in their health when readings measured outside of their clinically indicated range, leading to often unanticipated condition exacerbation. Participants described the TM system as appropriate, suggesting that they understood the purpose of TM as part of their normal work, aligning with the NPT construct of cognitive participation that identifies how patients engaged with TM, accepting the technology in part as a replacement for traditional care practices. Patients accepted the idea of their new work in TM, in part because these devices were connected to the nurse. In many cases, an appointment was not necessary because of the virtual connections made 
through the TM to the clinic, creating further patient engagement and willingness to accept TM.

\section{A Cyclical Evaluation of Collective Action and Appraisal}

Participants described an ongoing cyclical process in which the collective actions required to adopt TM resulted in a cycle of evaluation and readoption (ie, construct of reflexive monitoring) over time. In some cases, implementing TM requires embedding new routines at home or adjusting existing ones. Patients described clinicians, particularly the nurse, calling to check-in on questionable readings. Given the strong support of caregivers in our participant group, NPT might suggest that caregivers played an integral role as contributors to the relational work required in adopting TM technology (ie, collective action). The collective actions, which demonstrated engagement in the care process, reinforced patients' reflections on the value of the technology to be positive. This led to further engagement, greater collective action, involvement of family caregivers, and overall feasibility, such that patients wanted to continue TM use after the study.

\section{Adherence to TM in CCCs}

The results indicated an average adherence rate of $77.2 \%$ (142/184) in HF monitoring, 55\% (29/52) in HTN monitoring, and $72 \%$ (19/26) in DM monitoring. Previous research has found varying adherence rates, typically between $40 \%$ and $90 \%$, to TM in HF [47,60,61]. Another study found that the average adherence rate to $\mathrm{BP}$ monitoring and blood sugar monitoring was $59.7 \%$ and $50.2 \%$, respectively [61]. In addition, other previous studies have found an initial drop in patient adherence during onboarding, followed by a steadier adherence rate over time $[47,48,60]$. In this case, an initial drop in adherence did not occur. A consistent overall adherence rate supports the feasibility of this multi-condition TM system. When comparing patients with HF who were adherent to physiological readings versus those who completed a full set including symptom questions, the average change in adherence was less than $10 \%$. This suggests that the majority of patients in this cohort were adherent to both readings and symptom questions.

Although the adherence rates reported in this study are comparatively high, we anticipate that they are likely higher than reported. Similar to other Medly studies [47], we did not have functionality, which would enable researchers to automatically account for periods when patients were unable to take readings for legitimate reasons (eg, admitted to hospital, traveling, device replacement, etc). Patients were asked to notify the team if they were going to miss a reading. In many cases, the clinical team was notified in advance, suggesting that adherence rates are higher than reported findings. It is also possible that a subset of the incomplete readings, such as missing symptom questions, was because of the Bluetooth connectivity issues. Although patients may have taken a set of readings, it is possible that a loss in network connectivity could have reported a missed reading on that day.

\section{Considerations of Fidelity in Multi-Condition TM}

The fidelity of the intervention was considered to contribute to the overall evaluation of TM feasibility in nurse-led care. The degree to which the intervention was delivered as intended is defined as intervention fidelity [41]. In this study, patients did not always complete the symptom questions, contributing to a difference in the adherence between a physiological reading and a full set across participants with HF and therefore lower fidelity to the original intervention. For patients with HF, adherence to completing the symptom questions was lower than completing only the physiological measures. Symptom questions may not have been completed for 3 reasons: (1) questions were not reflective of significant changes on a day-to-day basis, (2) questions were not relevant to how they felt that day (ie, determination of self-management), or (3) symptoms that are perceived as important to patients with CCCs may not be reflected in single-disease protocols. Therefore, the patient experience in the context of the combination of conditions monitored is important in evaluating the intervention's fidelity in nurse-led care.

\section{Feasibility}

On the basis of the patient experience, a multi-condition TM platform is feasible for patients with CCCs in an integrated nurse-led care model. Patients accepted and adopted the technology as demonstrated by a high level of adherence. Historically, the adoption and use of technology have had greater benefits in younger populations compared with older adults who may be less familiar with new technologies [62]. However, the wide age range across participants of both genders suggests the ability to use Medly does not appear to be associated with age or technology experience in this case. Although patients described being able to more clearly identify when something was not right while using TM, our results found that patients still relied somewhat on the clinical team to identify abnormalities. This contributed to adherence and continued use. This reliance on a clinical connection to their clinical or nurse-led team has been demonstrated in other research $[15,63,64]$.

\section{Implications for Research and Future Directions}

There are several implications for future multi-condition TM apps as well as scaling up existing programs that focus on populations with CCCs. Attempts to tailor specific symptom questions have already been initiated in other eHealth technologies such as the electronic patient-reported outcome tool [65]. Further research should be conducted to explore the content and frequency of symptom questions in CCCs. Given the lower level of adherence to symptom questions in this study, an evaluation may suggest subtle changes to the question content or the frequency of questions required by the algorithm. Future research could explore these adjustments within the Medly platform as well as other TM platforms.

More research is needed to explore the extent of caregiver support in TM as well as identify the criteria for suitable enrollment of certain patient subgroups that require caregiver support. It is possible that TM interventions for patients with CCCs could be expanded if the implications of caregiver support and the role of caregivers are more broadly understood.

Finally, given the historically high rates of health care utilization in complex populations and the need for physical distancing 
because of infectious diseases such as COVID-19, TM solutions that improve patient experience should be explored as viable solutions to avoid in-person appointments while continuing to monitor complex patients closely, manage care needs remotely, and mitigate unanticipated visits to the emergency department.

\section{Strengths and Limitations}

The strengths of this study include the depth of the interview data collected as well as the rigorous approach to analysis using 2 trained qualitative coders and 2 theoretical frameworks (NPT and IOs). Interviews were candid, and diverse participants appeared to be forthcoming in their experiences using TM and perspectives on how to move forward with TM in nurse-led care. Given the nature of evaluating the initial feasibility of TM in nurse-led care for this population, the use of NPT and IOs worked well. There is an opportunity to use other well-known theoretical frameworks in future research, such as the Unified Theory of Acceptance Use of Technology 2 that undertakes a deeper dive in constructs such as price value, hedonic motivation, and effort expectancy in a program implementation.

There are several limitations to this study. First, the heterogeneous sample size was small $(n=26)$, with only few patients using TM to monitor more than one condition. In an effort to capture the broad spectrum of CCCs, we did not attempt to randomize our sample. Only a small number of participants monitored HTN or DM exclusively. It is possible that different adherence results may have been experienced with more multi-condition TM participants. Second, as participants were conveniently sampled based on the recruitment criteria and not randomly selected, a selection bias is possible within the study sample. Third, a defective phone battery in several phones during the study generated the illusion of nonadherence, but for legitimate reasons. Owing to delayed shipping, these participants were unable to synchronize readings from the devices to the phone, likely lowering the apparent adherence data. Due to the low response rate of the SF-36, we were unable to incorporate it into our analysis. Finally, participants were only followed up for 6 months; therefore, adherence after the study period remained unknown as well as an optimal duration of TM in this population.

\section{Conclusions}

Patients with CCCs perceived TM within a nurse-led care model to be feasible based on their experience using a multi-condition TM platform for 6 months. Overall, this study found promising adherence rates across the 3 conditions monitored by TM in this study. Patients monitoring HF demonstrated the highest rates of adherence at $77.2 \%(142 / 184)$ of the days in the study period. The qualitative results enabled an exploration of the feasibility of multi-condition TM, which could then be mapped to the constructs of NPT and IOs. Given the experiences of patients with CCCs, TM via multi-condition platforms in nurse-led care models should be considered to meet the growing need for virtual care interventions to support remote care of CCCs in the future.

\section{Conflicts of Interest}

None declared.

\section{Multimedia Appendix 1}

Patient interview questions.

[DOCX File, 16 KB-Multimedia Appendix 1]

\section{References}

1. Marengoni A, Angleman S, Melis R, Mangialasche F, Karp A, Garmen A, et al. Aging with multimorbidity: A systematic review of the literature. Ageing Research Reviews 2011 Sep;10(4):430-439. [doi: 10.1016/j.arr.2011.03.003]

2. Sakib MN, Shooshtari S, St John P, Menec V. The prevalence of multimorbidity and associations with lifestyle factors among middle-aged Canadians: an analysis of Canadian Longitudinal Study on Aging data. BMC Public Health 2019 Feb 28;19(1):243 [FREE Full text] [doi: 10.1186/s12889-019-6567-x] [Medline: 30819126]

3. Gruneir A, Bronskill SE, Maxwell CJ, Bai YQ, Kone AJ, Thavorn K, et al. The association between multimorbidity and hospitalization is modified by individual demographics and physician continuity of care: a retrospective cohort study. BMC Health Serv Res 2016 Apr 27;16:154 [FREE Full text] [doi: 10.1186/s12913-016-1415-5] [Medline: 27122051]

4. Mondor L, Maxwell CJ, Hogan DB, Bronskill SE, Gruneir A, Lane NE, et al. Multimorbidity and healthcare utilization among home care clients with dementia in Ontario, Canada: A retrospective analysis of a population-based cohort. PLoS Med 2017 Mar;14(3):e1002249 [FREE Full text] [doi: 10.1371/journal.pmed.1002249] [Medline: 28267802]

5. Skinner HG, Coffey R, Jones J, Heslin KC, Moy E. The effects of multiple chronic conditions on hospitalization costs and utilization for ambulatory care sensitive conditions in the United States: a nationally representative cross-sectional study. BMC Health Serv Res 2016 Mar 1;16(1):1-8. [doi: 10.1186/s12913-016-1304-y]

6. O'Brien R, Wyke S, Guthrie B, Watt G, Mercer S. An 'endless struggle': a qualitative study of general practitioners' and practice nurses' experiences of managing multimorbidity in socio-economically deprived areas of Scotland. Chronic Illn 2011 Mar;7(1):45-59. [doi: 10.1177/1742395310382461] [Medline: 20974642]

7. Aoki T, Yamamoto Y, Ikenoue T, Onishi Y, Fukuhara S. Multimorbidity patterns in relation to polypharmacy and dosage frequency: a nationwide, cross-sectional study in a Japanese population. Sci Rep 2018 Feb 28;8(1):-. [doi:

10.1038/s41598-018-21917-6] [Medline: 29491441] 
8. Gallacher K, May CR, Montori VM, Mair FS. Understanding patients' experiences of treatment burden in chronic heart failure using normalization process theory. Ann Fam Med 2011;9(3):235-243 [FREE Full text] [doi: 10.1370/afm.1249] [Medline: 21555751]

9. Violan C, Foguet-Boreu Q, Flores-Mateo G, Salisbury C, Blom J, Freitag M, et al. Prevalence, determinants and patterns of multimorbidity in primary care: a systematic review of observational studies. PLoS One 2014;9(7):e102149 [FREE Full text] [doi: 10.1371/journal.pone.0102149] [Medline: 25048354]

10. Heale R, James S, Garceau M. A multiple-case study in nurse practitioner-led clinics: an exploration of the quality of care for patients with multimorbidity. Nurs Leadersh (Tor Ont) 2016;29(3):37-45. [doi: 10.12927/cjnl.2016.24891] [Medline: 28032834]

11. Young J, Eley D, Patterson E, Turner C. A nurse-led model of chronic disease management in general practice: Patients' perspectives. Aust Fam Physician 2016 Dec;45(12):912-916 [FREE Full text] [Medline: 27903043]

12. Gordon K, Gray C, Dainty K, deLacy J, Seto E. Nurse-Led Models of Care for Patients with Complex Chronic Conditions: A Scoping Review. Nurs Leadersh (Tor Ont) 2019 Sep;32(3):57-76. [doi: 10.12927/cjnl.2019.25972] [Medline: 31714207]

13. Heale R, Wenghofer E, James S, Garceau M. Quality of Care for Patients With Diabetes and Mulitmorbidity Registered at Nurse Practitioner-Led Clinics. Can J Nurs Res 2018 Mar;50(1):20-27. [doi: 10.1177/0844562117744137] [Medline: 29216748]

14. Hansen K, McDonald C, O'Hara S, Post L, Silcox S, Gutmanis I. A formative evaluation of a nurse practitioner-led interprofessional geriatric outpatient clinic. J Interprof Care Internet 2017 Apr 06:546 [FREE Full text] [doi: 10.1080/13561820.2017.1303463] [Medline: 28388276]

15. Gordon K, Steele Gray C, Dainty KN, DeLacy J, Ware P, Seto E. Exploring an Innovative Care Model and Telemonitoring for the Management of Patients With Complex Chronic Needs: Qualitative Description Study. JMIR Nursing 2020 Mar 6;3(1):e15691. [doi: 10.2196/15691]

16. Heale R, James S, Wenghofer E, Garceau M. Nurse practitioner's perceptions of the impact of the nurse practitioner-led clinic model on the quality of care of complex patients. Prim Health Care Res Dev 2018 Jan 9;19(6):553-560. [doi: $10.1017 / \mathrm{s} 1463423617000913]$

17. Steele GC, Khan A, Kuluski K, McKillop I, Sharpe S, Bierman A. Improving Patient Experience and Primary Care Quality for Patients With Complex Chronic Disease Using the Electronic Patient-Reported Outcomes Tool: Adopting Qualitative Methods Into a User-Centered Design Approach. JMIR Res Protoc Internet 2016;5(1):e28 [FREE Full text] [doi: 10.2196/resprot.5204] [Medline: 26892952]

18. Paré G, Jaana M, Sicotte C. Systematic Review of Home Telemonitoring for Chronic Diseases?: The Evidence Base Home Telemonitoring?: A Definition. Journal of American Medical Informatics Association 2007;14(3):269-277. [doi: 10.1197/jamia.M2270] [Medline: 17329725]

19. Kitsiou S, Paré G, Jaana M. Effects of home telemonitoring interventions on patients with chronic heart failure: an overview of systematic reviews. J Med Internet Res 2015 Mar 12;17(3):e63 [FREE Full text] [doi: 10.2196/jmir.4174] [Medline: 25768664]

20. Kitsiou S, Paré G, Jaana M, Gerber B. Effectiveness of mHealth interventions for patients with diabetes: an overview of systematic reviews. PLoS One 2017;12(3):e0173160 [FREE Full text] [doi: 10.1371/journal.pone.0173160] [Medline: 28249025]

21. Queirós A, Alvarelhão J, Cerqueira M, Silva A, Santos M, Pacheco Rocha N. Remote Care Technology: A Systematic Review of Reviews and Meta-Analyses. Technologies 2018 Feb 10;6(1):22. [doi: 10.3390/technologies6010022]

22. Pekmezaris R, Tortez L, Williams M, Patel V, Makaryus A, Zeltser R, et al. Home Telemonitoring In Heart Failure: A Systematic Review And Meta-Analysis. Health Aff (Millwood) 2018 Dec;37(12):1983-1989. [doi: 10.1377/hlthaff.2018.05087] [Medline: 30633680]

23. Yun J, Park J, Park H, Lee H, Park D. Comparative Effectiveness of Telemonitoring Versus Usual Care for Heart Failure: A Systematic Review and Meta-analysis. J Card Fail 2018 Jan;24(1):19-28. [doi: 10.1016/j.cardfail.2017.09.006] [Medline: 28939459]

24. Cruz J, Brooks D, Marques A. Home telemonitoring effectiveness in COPD: a systematic review. Int J Clin Pract 2014 Mar;68(3):369-378. [doi: 10.1111/ijcp.12345] [Medline: 24472009]

25. He T, Liu X, Li Y, Wu Q, Liu M, Yuan H. Remote home management for chronic kidney disease: A systematic review. J Telemed Telecare 2016 Jul 09;23(1):3-13. [doi: 10.1177/1357633x15626855]

26. Achelrod D, Schreyögg J, Stargardt T. Health-economic evaluation of home telemonitoring for COPD in Germany: evidence from a large population-based cohort. Eur J Health Econ 2017 Sep;18(7):869-882 [FREE Full text] [doi: 10.1007/s10198-016-0834-x] [Medline: 27699567]

27. Seto E, Leonard KJ, Cafazzo JA, Barnsley J, Masino C, Ross HJ. Mobile phone-based telemonitoring for heart failure management: a randomized controlled trial. J Med Internet Res 2012 Feb 16;14(1):e31 [FREE Full text] [doi: 10.2196/jmir.1909] [Medline: 22356799]

28. Paré G, Moqadem K, Pineau G, St-Hilaire C. Clinical effects of home telemonitoring in the context of diabetes, asthma, heart failure and hypertension: a systematic review. J Med Internet Res 2010 Jun 16;12(2):e21 [FREE Full text] [doi: 10.2196/jmir.1357] [Medline: 20554500] 
29. Mochari-Greenberger H, Vue L, Luka A, Peters A, Pande RL. A Tele-Behavioral Health Intervention to Reduce Depression, Anxiety, and Stress and Improve Diabetes Self-Management. Telemed J E Health 2016 Aug;22(8):624-630. [doi: 10.1089/tmj.2015.0231] [Medline: 26954880]

30. Lee JY, Chan CKY, Chua SS, Ng CJ, Paraidathathu T, Lee KKC, et al. Telemonitoring and Team-Based Management of Glycemic Control on People with Type 2 Diabetes: a Cluster-Randomized Controlled Trial. J Gen Intern Med 2020 Jan;35(1):87-94. [doi: 10.1007/s11606-019-05316-9] [Medline: 31512187]

31. Kim Y, Park J, Lee B, Jung C, Park D. Comparative effectiveness of telemonitoring versus usual care for type 2 diabetes: A systematic review and meta-analysis. J Telemed Telecare 2018 Jul 17;25(10):587-601. [doi: 10.1177/1357633x18782599]

32. Margolis KL, Asche SE, Dehmer SP, Bergdall AR, Green BB, Sperl-Hillen JM, et al. Long-term Outcomes of the Effects of Home Blood Pressure Telemonitoring and Pharmacist Management on Blood Pressure Among Adults With Uncontrolled Hypertension: Follow-up of a Cluster Randomized Clinical Trial. JAMA Netw Open 2018 Sep 7;1(5):e181617 [FREE Full text] [doi: 10.1001/jamanetworkopen.2018.1617] [Medline: 30646139]

33. Duan Y, Xie Z, Dong F, Wu Z, Lin Z, Sun N, et al. Effectiveness of home blood pressure telemonitoring: a systematic review and meta-analysis of randomised controlled studies. J Hum Hypertens 2017 Jul;31(7):427-437. [doi: 10.1038/jhh.2016.99] [Medline: 28332506]

34. Sicotte C, Paré G, Morin S, Potvin J, Moreault M. Effects of home telemonitoring to support improved care for chronic obstructive pulmonary diseases. Telemed J E Health 2011 Mar;17(2):95-103. [doi: 10.1089/tmj.2010.0142] [Medline: 21214399]

35. Seto E, Leonard KJ, Cafazzo JA, Barnsley J, Masino C, Ross HJ. Perceptions and experiences of heart failure patients and clinicians on the use of mobile phone-based telemonitoring. J Med Internet Res 2012 Feb 10;14(1):e25 [FREE Full text] [doi: 10.2196/jmir.1912] [Medline: 22328237]

36. Walker R, Tong A, Howard K, Palmer S. Patient expectations and experiences of remote monitoring for chronic diseases: Systematic review and thematic synthesis of qualitative studies. Int J Med Inform 2019 Apr;124:78-85 [FREE Full text] [doi: 10.1016/j.ijmedinf.2019.01.013] [Medline: 30784430]

37. Ong MK, Romano PS, Edgington S, Aronow HU, Auerbach AD, Black JT, Better Effectiveness After Transition-Heart Failure (BEAT-HF) Research Group. Effectiveness of Remote Patient Monitoring After Discharge of Hospitalized Patients With Heart Failure: The Better Effectiveness After Transition -- Heart Failure (BEAT-HF) Randomized Clinical Trial. JAMA Intern Med 2016 Mar;176(3):310-318 [FREE Full text] [doi: 10.1001/jamainternmed.2015.7712] [Medline: 26857383]

38. Koehler F, Koehler K, Deckwart O, Prescher S, Wegscheider K, Kirwan B, et al. Efficacy of telemedical interventional management in patients with heart failure (TIM-HF2): a randomised, controlled, parallel-group, unmasked trial. Lancet 2018 Sep;392(10152):1047-1057. [doi: 10.1016/s0140-6736(18)31880-4]

39. Kruse C, Pesek B, Anderson M, Brennan K, Comfort H. Telemonitoring to Manage Chronic Obstructive Pulmonary Disease: Systematic Literature Review. JMIR Med Inform 2019 Mar 20;7(1):e11496 [FREE Full text] [doi: 10.2196/11496] [Medline: 30892276]

40. Sul A, Lyu D, Park D. Effectiveness of telemonitoring versus usual care for chronic obstructive pulmonary disease: A systematic review and meta-analysis. J Telemed Telecare 2018 Dec 12;26(4):189-199. [doi: 10.1177/1357633x18811757]

41. Proctor E, Silmere H, Raghavan R, Hovmand P, Aarons G, Bunger A, et al. Outcomes for implementation research: conceptual distinctions, measurement challenges, and research agenda. Adm Policy Ment Health 2011 Mar;38(2):65-76 [FREE Full text] [doi: 10.1007/s10488-010-0319-7] [Medline: 20957426]

42. van Walraven C, Dhalla IA, Bell C, Etchells E, Stiell IG, Zarnke K, et al. Derivation and validation of an index to predict early death or unplanned readmission after discharge from hospital to the community. Can Med Assoc J 2010 Apr 6;182(6):551-557 [FREE Full text] [doi: 10.1503/cmaj.091117] [Medline: 20194559]

43. May C, Mair F, Finch T, MacFarlane A, Dowrick C, Treweek S. Development of a theory of implementation and integration: Normalization Process Theory. Implement Science 2009(1):29 [FREE Full text] [doi: 10.1186/1748-5908-4-29]

44. May C, Finch T. Implementing, Embedding, and Integrating Practices: An Outline of Normalization Process Theory. Sociology 2009 Jun 15;43(3):535-554. [doi: 10.1177/0038038509103208]

45. Murray E, Treweek S, Pope C, MacFarlane A, Ballini L, Dowrick C, et al. Normalisation process theory: a framework for developing, evaluating and implementing complex interventions. BMC Med 2010 Oct 20;8:63 [FREE Full text] [doi: 10.1186/1741-7015-8-63] [Medline: 20961442]

46. May C. Towards a general theory of implementation. Implement Sci 2013 Feb 13;8:18 [FREE Full text] [doi: 10.1186/1748-5908-8-18] [Medline: 23406398]

47. Ware P, Dorai M, Ross H, Cafazzo J, Laporte A, Boodoo C. Patient adherence to a mobile phone?based heart failure telemonitoring program: A longitudinal mixed-methods study. Journal of Medical Internet Research 2019;21(2):1-18. [doi: $10.2196 / 13259]$

48. Seto E, Leonard KJ, Cafazzo JA, Masino C, Barnsley J, Ross HJ. Mobile phone-based remote patient monitoring improves heart failure management and outcomes: a randomized controlled trial. Journal of the American College of Cardiology 2011 Apr;57(14):E1260. [doi: 10.1016/s0735-1097(11)61260-6] 
49. Seto E, Leonard KJ, Cafazzo JA, Barnsley J, Masino C, Ross HJ. Developing healthcare rule-based expert systems: case study of a heart failure telemonitoring system. Int J Med Inform 2012 Aug;81(8):556-565. [doi: 10.1016/j.ijmedinf.2012.03.001] [Medline: 22465288]

50. Billingham SAM, Whitehead AL, Julious SA. An audit of sample sizes for pilot and feasibility trials being undertaken in the United Kingdom registered in the United Kingdom Clinical Research Network database. BMC Med Res Methodol 2013;13:104 [FREE Full text] [doi: 10.1186/1471-2288-13-104] [Medline: 23961782]

51. Julious SA. Sample size of 12 per group rule of thumb for a pilot study. Pharmaceut. Statist 2005 Oct;4(4):287-291. [doi: $10.1002 /$ pst.185]

52. Ware JE, Sherbourne CD. The MOS 36-ltem Short-Form Health Survey (SF-36). Medical Care 1992;30(6):473-483. [doi: 10.1097/00005650-199206000-00002]

53. May C. Agency and implementation: Understanding the embedding of healthcare innovations in practice. 2013 Feb;78:26-33. [doi: 10.1016/j.socscimed.2012.11.021]

54. Thorne S, Kirkham SR, MacDonald-Emes J. Interpretive description: A noncategorical qualitative alternative for developing nursing knowledge. Research in Nursing and Health 1997 Apr;20(2):169-177. [doi: 10.1002/(sici)1098-240x(199704)20:2<169::aid-nur9>3.0.co;2-i]

55. Thorne S, Kirkham S, MacDonald-Emes J. Interpretive description: a noncategorical qualitative alternative for developing nursing knowledge. Res Nurs Health 1997 Apr;20(2):169-177. [doi:

10.1002/(sici)1098-240x(199704)20:2<169::aid-nur9>3.0.co;2-i] [Medline: 9100747$]$

56. Hunt MR. Strengths and Challenges in the Use of Interpretive Description: Reflections Arising From a Study of the Moral Experience of Health Professionals in Humanitarian Work. Qual Health Res 2009 Aug 18;19(9):1284-1292. [doi: $10.1177 / 1049732309344612]$

57. Hennink MM, Kaiser BN, Marconi VC. Code Saturation Versus Meaning Saturation. Qual Health Res 2016 Sep 26;27(4):591-608. [doi: 10.1177/1049732316665344]

58. Saunders B, Sim J, Kingstone T, Baker S, Waterfield J, Bartlam B, et al. Saturation in qualitative research: exploring its conceptualization and operationalization. Qual Quant 2017 Sep 14;52(4):1893-1907. [doi: 10.1007/s11135-017-0574-8]

59. Census Profile. Brampton, Ontario. 2016. URL: https://www12.statcan.gc.ca/census-recensement/2016/dp-pd/prof/details/ Page.

cfm?Lang=E\&Geo1=CSD\&Code1=3521010\&Geo2=PR\&Code2=35\&Data=Count\&SearchText=Toronto\&SearchType=Begins\&SearchPR=01\&B1=All [accessed 2018-01-01]

60. Maeder A, Poultney N, Morgan G, Lippiatt R. Patient Compliance in Home-Based Self-Care Telehealth Projects. J Telemed Telecare 2015 Nov 10;21(8):439-442. [doi: 10.1177/1357633x15612382]

61. Celler B, Argha A, Varnfield M, Jayasena R. Patient Adherence to Scheduled Vital Sign Measurements During Home Telemonitoring: Analysis of the Intervention Arm in a Before and After Trial. JMIR Med Info 2018;6(2):e15. [doi: 10.2196/preprints.9200] [Medline: 29631991]

62. Lee C. Adoption of Smart Technology Among Older Adults: Challenges and Issues. Publ Pol Aging Rep 2013 Dec 17;24(1):14-17. [doi: 10.1093/ppar/prt005]

63. Kuluski K, Peckham A, Gill A, Gagnon D, Dumas S, Sheridan N, et al. What is important to people with multimorbidity and their caregivers? Identifying attributes of person centred primary health care from the user perspective. Int J Integr Care 2019 Aug 08;19(4):271. [doi: 10.5334/ijic.s3271]

64. Bayliss EA, Edwards AE, Steiner JF, Main DS. Processes of care desired by elderly patients with multimorbidities. Fam Pract 2008 Aug;25(4):287-293 [FREE Full text] [doi: 10.1093/fampra/cmn040] [Medline: 18628243]

65. Steele Gray C, Gill A, Khan AI, Hans PK, Kuluski K, Cott C. The Electronic Patient Reported Outcome Tool: Testing Usability and Feasibility of a Mobile App and Portal to Support Care for Patients With Complex Chronic Disease and Disability in Primary Care Settings. JMIR mHealth uHealth 2016 Jun 02;4(2):e58. [doi: 10.2196/mhealth.5331]

\author{
Abbreviations \\ BP: blood pressure \\ CCC: complex chronic condition \\ DM: diabetes mellitus \\ HF: heart failure \\ HTN: hypertension \\ IOs: Implementation Outcomes \\ NP: nurse practitioner \\ NPT: normalization process theory \\ SF-36: $36-$ Item Short Form Survey \\ TM: telemonitoring \\ WT: weight
}


Edited by E Borycki; submitted 10.07.20; peer-reviewed by R Booth, C Jacob, J Walsh; comments to author 10.08.20; revised version received 17.08.20; accepted 23.08.20; published 29.09.20

Please cite as:

Gordon K, Dainty KN, Steele Gray C, DeLacy J, Shah A, Resnick M, Seto E

Experiences of Complex Patients With Telemonitoring in a Nurse-Led Model of Care: Multimethod Feasibility Study

JMIR Nursing 2020;3(1):e22118

URL: https://nursing.jmir.org/2020/1/e22118/

doi: $10.2196 / 22118$

PMID: $\underline{34406972}$

CKayleigh Gordon, Katie N Dainty, Carolyn Steele Gray, Jane DeLacy, Amika Shah, Myles Resnick, Emily Seto. Originally published in JMIR Nursing Informatics (https://nursing.jmir.org), 29.09.2020. This is an open-access article distributed under the terms of the Creative Commons Attribution License (https://creativecommons.org/licenses/by/4.0/), which permits unrestricted use, distribution, and reproduction in any medium, provided the original work, first published in the Journal of Medical Internet Research, is properly cited. The complete bibliographic information, a link to the original publication on http://www.jmir.org/, as well as this copyright and license information must be included. 